\title{
Journal of \\ Surgery
}

\section{Endoscopic Treatment of Gastric Fundus Fistula after Sleeve Gastrectomy: A Case Report}

\begin{abstract}
Keywords: Gastric fundus fistula; Sleeve gastrectomy; Endoscopy Abstract

Introduction: Gastric fistulas post sleeve gastrectomy is one of the most severe complications and can be found up to $5,3 \%$. Surgical therapies to persistent gastric fistulas are technically difficult and sometimes inefficient. Therefore, new endoscopic techniques have been increasingly being researched in order to treat this surgical complication. Our study aims to describe a case report which the patient presented a gastric fistula post SG. This complication was treated by endoscopic approach.

Case report A 39 year old caucasian male underwent videolaparascopiccholecistechtomy and SG, in April 2012 in a large hospital in Curitiba. Regarding the pre operation evalution, the patient presented a BMl of 50.15 associated with hepatic steatosis and cholelithiasis. In the $43^{\text {th }}$ day $\mathrm{PO}$, an upper endoscopic was performed and visualized and gastric fistula of $0.5 \mathrm{~cm}$ in proximal anterior wall, right above the cardia. Four upper endoscopies were performed in order to reduce the fistula. The procedure was successful and the fistula was completely closed.
\end{abstract}

Conclusion: The upper digestive endoscopy represents a reliable and effective method not only to diagnose but also to treat possible complication, even when they occur in infrequent anatomic areas like the one we presented in this case report.

\section{Introduction}

Sleeve gastrectomy (SG) is a partial gastrectomy in which the greater stomach curvature is surgically removed, resulting in a tubelike structure (Figure 1). SG was initially indicated for patients with obesity (BMI $\left.>40 \mathrm{~kg} / \mathrm{m}^{2}\right)$ as the first step to biliopancreatic diversion $[1,2]$. However, SG is increasingly being performed as a stand-alone operation with good weight loss and the resolution of obesity-related comorbidities [3-6].

SG presents low complication rates (3-24\%) and even lower mortality rates $(0.39 \%)$. Further, this technique is technically easier than any of the alternatives, multiple anastomosis are not required (7-16\%). Still, even with these low complication rates, the potential for such events should not be under estimated.

A recent PubMed research on mortality and morbidity after SG returned only 17 studies, representing 810 procedures and their complication rates. Table 1 illustrates the total complications related to the type of surgical procedure; no similarities among the complications were noted. Furthermore, re-operation, the most common post-SG complication, was necessary in 3.6\% of cases [7]. Gastric fistulas post-SG remainone of the most severe complications and were found in up to $5.3 \%$ [5-24].

The majority of gastric leaks arise due to specific aspects of the staple line, such as inadequate blood supply and oxygenation, which can directly affect the healing process. Fistulas can also occur due to gastric ischemia resulting from the great amount of heat generated
Marcos Fabiano Sigwalt ${ }^{1}$, Julio Cesar Wiederkehr ${ }^{2,5}$ Rodolfo Lara de Macedo ${ }^{3,6}$, Caroline A. de Carvalho ${ }^{4,5}$ Henrique A. Wiederkehr ${ }^{4,5}$ and Camila Vitola Pasetto ${ }^{4,5}$

${ }^{1}$ Professor, Department of Surgery, Positivo University; Performed research; Wrote the paper

${ }^{2}$ Associated Professor, Department of Surgery, Federal University of Parana; Contributed Important reagents

${ }^{3}$ Medical Intern, Department of Surgery, Hospital das Clínicas, Curitiba,Brazil; Contributed important reagents

${ }^{4}$ Medical Students from Faculdade Evangélica do Paraná, Curitiba, Paraná, Brazil; Collected data; Wrote the paper

${ }^{5}$ Analyzed data; Wrote the paper

${ }^{6}$ Contributed important reagents

${ }^{7}$ Analyzed data

*Address for Correspondence

Marcos Fabiano Sigwalt, Professor, Department of Surgery, Positivo University, Curitiba, Paraná, 80240-130, Brazil, Tel: 5541 88644816;

E-mail: marcossigwalt@yahoo.com.br

Copyright: (c) 2014 Sigwalt MF, et al. This is an open access article distributed under the Creative Commons Attribution License, which permits unrestricted use, distribution, and reproduction in any medium, provided the original work is properly cited.

Submission: 09 November 2014

Accepted: 03 December 2014

Published: 08 December 2014

Reviewed \& Approved by: Dr. Michael Leitman, Professor of Surgery, Icahn School of Medicine at Mount Sinai, USA

Table 1: Incidence of complications after sleeve gastrectomy.

\begin{tabular}{|l|c|c|}
\hline Complication & N & $\%$ \\
\hline Reoperation & 29 & 3.6 \\
\hline Fistula & 7 & 0,8 \\
\hline Extended time on ventilator & 5 & 0.6 \\
\hline Stenosis & 6 & 0.7 \\
\hline Renal insufficiency & 4 & 0.5 \\
\hline Post-operative bleeding & 3 & 0.4 \\
\hline Atelectasis & 2 & 0.2 \\
\hline Pulmonary embolism & 2 & 0.2 \\
\hline Delayed gastric emptying & 2 & 0.2 \\
\hline Gastric dilation & 1 & 0.1 \\
\hline Persistent vomiting & 1 & 0.1 \\
\hline Subphrenicabcess & 2 & 0.2 \\
\hline Urinary infection & 1 & 0.1 \\
\hline Death & 4 & 0.5 \\
\hline
\end{tabular}

by the cautery used during a surgical procedure [20]. Although the stomach is well-vascularized, the gastroesophageal junction represents an area of decreased vascularity and thus is more prone to leaks. Further, the stomach tends to be thinner at the angle of His, and some authors believe that the large staple height does not adequately seal this area of the stomach $[25,26]$.

The surgical principles applied during gastric leak treatment include the following: high specter antibiotics, identification and repair of the defect, hydration and contamination control, external drainage of the contaminated area, and enteral feeding. Regarding stable patients, percutaneous drainage represents a reasonable 


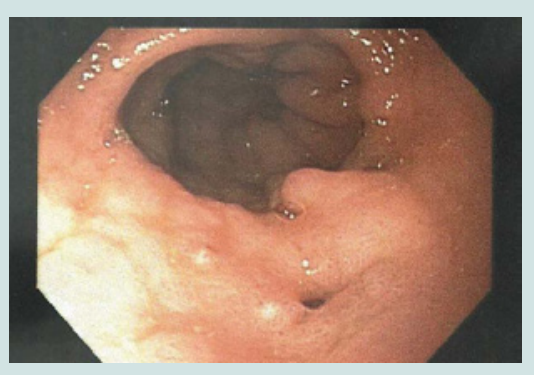

Figure 1: Endoscopy performed on day $43^{\text {th }}$ day PO demonstrating the presence of a gastric fistula.

alternative [27]. Surgical therapies for persistent gastric fistulas are technically difficult and sometimes ineffective. Therefore, new endoscopic techniques have been increasingly being researched to treat this surgical complication.

One new technique is the use of stents, which provide an endoscopic approach to deviating the gastrointestinal flux away from the fistula. Moreover, the stents should totally or partially cover the fistula. If the stents totally cover the defect, they are easier to remove without damaging the gastric mucosa. Stent migration is the most common complication of esophagic and gastric stents [28,29].

The endoscopic application of glue constitutes an alternative option for occluding the leak. Some authors have performed this procedure as a primary treatment, but frequently, other applications are required. Thus, this technique is usually combined with other procedures [30-34]

Regarding the use of endoscopic clips, there are a few studies that may be supported by sufficient evidence to indicate the use of this procedure as a therapeutic option. Clip durability and efficacy are not totally clarified; therefore, this procedure cannot be indicated as a therapeutic option $[28,35,36]$.

In a recent study, Bege et al., proposed endoscopic management as a therapeutic method for post-bariatric surgery fistulas and achieved a high success rate. This approach is composed of three steps: peritoneal washes and peri-anastomic fluid drainage, fistula deviation by applying the stent and closure of the fistula space with clips or surgical glue [36,37]. Thanks to this study, the endoscopic approach has become feasible; unnecessary surgical interventions can now be avoided.

Our study aims to describe a case report in which the patient presented a gastric fistula post-SG. This complication was treated by an endoscopic approach.

\section{Presentation of the Case}

In April 2012, a 39-year-old male underwent video laparascopic cholecystectomy and SG in a large hospital in Curitiba. Regarding the pre-operation evaluation, the patient presented with a BMI of 50.15 associated with hepatic steatosis and cholelithiasis.

After ten post-operatory (PO) days, the patient developed acute moderate pain in his left flank associated with fever $\left(38^{\circ} \mathrm{C}\right)$ within 48 $\mathrm{h}$ and progressive dyspnea. The CT scan demonstrated a left pleural effusion, left inferior lobe atelectasis, pneumoperitoneum, hypodense collections, hydroaeric level in the left subdiaphragmatic region, andperisplenic and perigrastric parallels to the staple line.

Based on the laboratory values, leukocytosis with a left shift was observed; in response, IV antibiotic therapy with Ceftriaxone and Metronidazol was prescribed for 5 days in association with parenteral nutrition.

In the $11^{\text {th }} \mathrm{PO}$, the patient underwent a laparotomy with the drainage of the pus collected near the biliary impression. The methylene blue test demonstrated no leaking, and two laminar drains were placed. After the surgery, the patient was transferred to the intensive care unit and was prescribed meropenem, nitroglycerin, sedatives and orotracheal intubation.

Another drainage was performed laparoscopically on the $26^{\text {th }}$ day PO. The collection was purulent and hemorrhagic in the perisplenic and perigastric region. After the procedure, the patient remained at the ICU until the $36^{\text {th }}$ day.

On the $43^{\text {th }}$ day PO, an upper endoscopy was performed to visualize the gastric fistula of $0.5 \mathrm{~cm}$ (Figure 1) at the proximal anterior wall, right above the cardia. A duodenal fistula next to the papilla was also diagnosed with positive culture for Proteus mirabilis, calling for a continuation of the prescribed antibiotics.

On the $60^{\text {th }}$ day PO, an abdominal CT scan diagnosed a pneumoperitoneum between the liver and stomach, whereas a left septated pleural effusion was observed in the thoracic CT scan and treated with Tazocin, Vancomycin and thoracocentesis associated with a decortication procedure later on the $64^{\text {th }}$ day PO.

The third surgical intervention was completed on the $69^{\text {th }}$ day PO as a protective ileostomy and jejunostomy for feeding purposes. Then, 4 upper endoscopies were performed to reduce the fistula (Figures $2-4)$. The procedure was successful, and the fistula was completely closed.

\section{Discussion}

Obesity is one of the most important chronic diseases affecting all age groups. Surgical procedures designed to achieve weight loss in moderate to severe obesity have shown better results than clinical treatments [38].

In March 2011, an event was held in Florida to discuss the results of 12,000 patients who underwent video laparoscopic SG to treat their morbid obesity. It was concluded that this technique alone could be used to treat this condition (90\%). Further, this approach was considered as an alternative for high-risk patients (96\%); transplant candidates, both kidney and liver (96\%); patients with metabolic syndrome, a BMI of $30-35 \mathrm{~kg} / \mathrm{m}^{2}$, and associated comorbidities (95\%); inflammatory intestinal disease (86\%); morbid obesity in adolescents (77\%); elderly morbid obese patients (100\%) and child A or B patients (78\%) [39].

Fistulas remain one of the most common SG complications, alongside stenosis, bleeding and GERD. The location of these fistulas is usually at the staple line and/or next to the angle of His. Gastrocolic and gastropulmonary fistulas can also occur [39-42], although gastric fundus fistulas were not reported in our bibliography. 
Citation: Sigwalt MF, Wiederkehr JC, de Macedo RL, de Carvalho CA, Wiederkehr HA, et al. Endoscopic Treatment of Gastric Fundus Fistula after Sleeve Gastrectomy: A Case Report. J Surgery. 2014;2(2): 5.
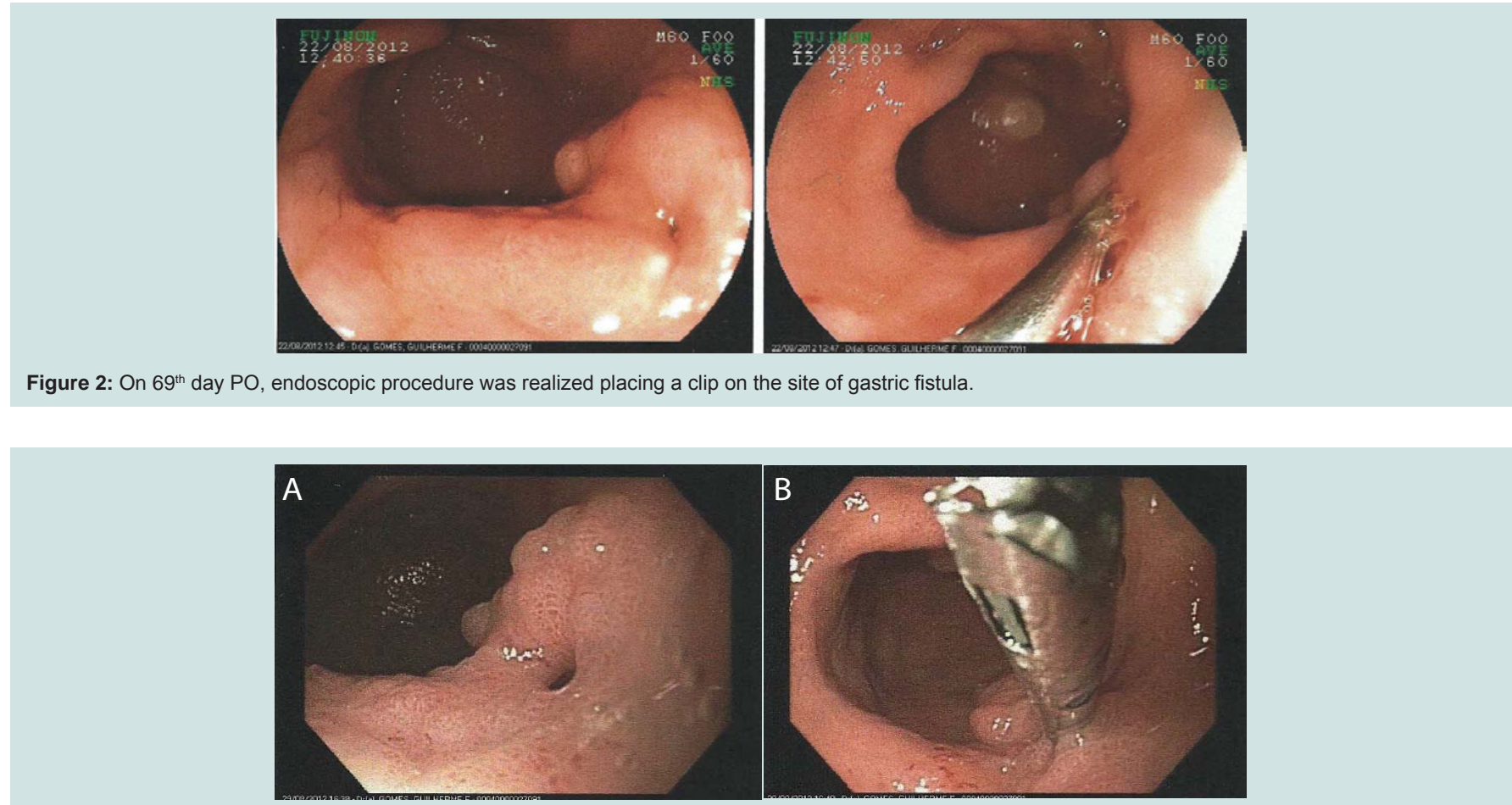

Figure 3: Second endoscopic procedure performed seven days after the previous one, showing the gastric fistulous orifice (A) and the clip placed on the site of gastric fistula (B).

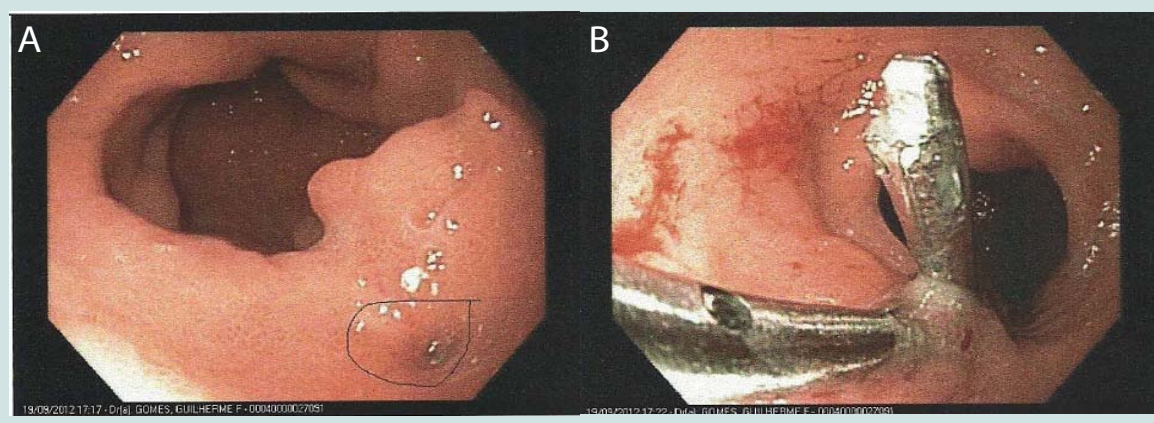

Figure 4: Endoscopic procedure, performed almost a month after the first, showing a significant decrease in gastric fistulous orifice (A) and placing another clip in the remnant fistulous orifice (B).

Usually, in the earliest days after a bariatric surgery associated with intracavitary infection due to gastric fistula, the patient presents with dyspnea and tachycardia. Because these patients are obese, their acute abdominal symptoms may vary from painful, diffuse palpation of the abdomen to no clear signs of peritonitis [39].

The left lung is frequently involved in a worse clinical outcome due to subphrenic infection. This finding can be noticed in radiologic exams, which present with atelectasis, pleura effusion, empyema, pulmonary abscess and in some cases communication of the fistula to bronchi [40].

According to Campos, upper digestive endoscopy could represent a means of great aid to bariatric surgery. This procedure can be performed 15 days from the onset of the infection; however, conditions that make the procedure impracticable, such as hemodynamic dysfunctions or lack of the minimum necessary equipment, should be excluded. The patient should be anesthetized to successfully perform an upper endoscopy [42].

If an upper endoscopy is performed during the early days of an infection, we are able to identify some important signs of fistula that could improve its healing process, such as the correct position of the fistula at the internal orifice, the presence of interior digestive tract drainage, foreign bodies within the fistula, necrotic tissue, the presence of a perigastric cavity that can be treated with a nasalcavitary tube, and, in some cases, migration of the gastric band. This procedure also has therapeutic applications, especially due to the application of biological glue, self-expandable prosthesis, endoclips or Surgisys [42].

It is internationally accepted that upper digestive endoscopy should be performed routinely in patients submitted to sleeve 
Citation: Sigwalt MF, Wiederkehr JC, de Macedo RL, de Carvalho CA, Wiederkehr HA, et al. Endoscopic Treatment of Gastric Fundus Fistula after Sleeve Gastrectomy: A Case Report. J Surgery. 2014;2(2): 5.

ISSN: 2332-4139

gastrectomy to improve their follow-up and to diagnose any possible complications early [39].

\section{Conclusion}

Despite the SG low complication rates, the potential for such events like fistulas, for example, should not be minimized.

The upper digestive endoscopy represents a reliable and effective method not only to diagnose but also to treat possible complications, even when they occur in infrequent anatomic areas like the one we presented in this case report.

\section{References}

1. Almogy G, Crookes PF, Anthone GJ (2004) Longitudinal gastrectomy as a treatment for the high-risk super-obese patient. Obes Surg 14: 492-497.

2. Regan JP, Inabnet WB, Gagner M, Pomp A (2003) Early experience with twostage laparoscopic Roux-en-Y gastric bypass as an alternative in the supersuper obese patient. Obes Surg 13: 861-864.

3. Chazelet C, Verhaeghe P, Perterli R, Fennich S, Houdart R, et al. (2009) Longitudinal sleeve gastrectomy as a stand-alone bariatric procedure: Results of a multicenter retrospective study. J Chir (Paris) 146: 368-372.

4. Sammour T, Hill AG, Singh P, Ranasinghe A, Babor R, et al. (2010) Laparoscopic sleeve gastrectomy as a single-stage bariatric procedure. Obes Surg 20: 271-275.

5. Tucker ON, Szomstein S, Rosenthal RJ (2008) Indications for sleeve gastrectomy as a primary procedure for weight loss in the morbidly obese. $J$ Gastrointest Surg 12: 662-667.

6. Fuks D, Verhaeghe P, Brehant O, Sabbagh C, Dumont F, et al. (2009) Results of laparoscopic sleeve gastrectomy: a prospective study in 135 patients with morbid obesity. Surgery 145: 106-113.

7. Frezza EE, Reddy S, Gee LL, Wachtel MS (2009) Complications after sleeve gastrectomy for morbid obesity. Obes Surg 19: 684-687.

8. Gagner M, Deitel M, Kalberer TL, Erickson AL, Crosby RD (2009) The Second International Consensus Summit for Sleeve Gastrectomy, March 1921, 2009. Surg Obes Relat Dis 5: 476.

9. Jones SB, Jones DB (2008) Obesity Surgery: Patient Safety and Best Practices. Cine-Med Inc, Woodbury.

10. Lalor PF, Tucker ON, Szomstein S, Rosenthal RJ (2008) Complications after laparoscopic sleeve gastrectomy. Surg Obes Relat Dis 4: 33-38.

11. Moon Han S, Kim WW, Oh JH (2005) Results of laparoscopic sleeve gastrectomy (LSG) at 1 year in morbidly obese Korean patients. Obes Surg 15: $1469-1475$

12. Himpens J, Dapri G, Cadière GB (2006) A prospective randomized study between laparoscopic gastric banding and laparoscopic isolated sleeve gastrectomy: results after 1 and 3 years. Obes Surg 16: 1450-1456.

13. Silecchia G, Boru C, Pecchia A, Rizzello M, Casella G, et al. (2006) Effectiveness of laparoscopic sleeve gastrectomy (first stage of biliopancreatic diversion with duodenal switch) on co-morbidities in super-obese high-risk patients. Obes Surg 16: 1138-1144.

14. Lee CM, Cirangle PT, Jossart GH (2007) Vertical gastrectomy for morbid obesity in 216 patients: report of two-year results. Surg Endosc 21: 18101816.

15. Hamoui N, Anthone GJ, Kaufman HS, Crookes PF (2006) Sleeve gastrectomy in the high-riskpatient. Obes Surg 16: 1445-1449.

16. Armstrong J, O'Malley SP (2010) Outcomes of sleeve gastrectomy for morbid obesity: a safe and effective procedure? Int J Surg 8: 69-71.

17. Trelles N, Gagner M (2007) Sleeve gastrectomy. Operative Techniques in General Surgery 9: 123.

18. Cottam D, Qureshi FG, Mattar SG, Sharma S, Holover S, et al. (2006)
Laparoscopic sleeve gastrectomy as an initial weight-loss procedure for highrisk patients with morbid obesity. Surg Endosc 20: 859-863.

19. Arias E, Martínez PR, Ka Ming Li V, Szomstein S, Rosenthal RJ (2009) Mid-term follow-up after sleeve gastrectomy as a final approach for morbid obesity. Obes Surg 19: 544-548.

20. Burgos AM, Braghetto I, Csendes A, Maluenda F, Korn O, et al. (2009) Gastric leak after laparoscopic-sleeve gastrectomy for obesity. Obes Surg 19: 1672-1677.

21. Roa PE, Kaidar-Person O, Pinto D, Cho M, Szomstein S, et al. (2006) Laparoscopic sleeve gastrectomy as treatment for morbid obesity: technique and short-term outcome. Obes Surg 16: 1323-1326.

22. Weiner RA, Weiner S, Pomhoff I, Jacobi C, Makarewicz W, et al. (2007) Laparoscopic sleeve gastrectomy--influence of sleeve size and resected gastric volume. Obes Surg 17: 1297-1305.

23. Melissas J, Koukouraki S, Askoxylakis J, Stathaki M, Daskalakis M, et al. (2007) Sleeve gastrectomy: a restrictive procedure? Obes Surg 17: 57-62.

24. Felberbauer FX, Langer F, Shakeri-Manesch S, Schmaldienst E, Kees $\mathrm{M}$, et al. (2008) Laparoscopic sleeve gastrectomy as an isolated bariatric procedure: intermediate-term results from a large series in three Austrian centers. Obes Surg 18: 814-818.

25. Baltasar A, Serra C, Pérez N, Bou R, Bengochea M, et al. (2005) Laparoscopic sleeve gastrectomy: a multi-purpose bariatric operation. Obes Surg 15: 1124 1128 .

26. Braghetto I, Korn O, Valladares H, Gutiérrez L, Csendes A, et al. (2007) Laparoscopic sleeve gastrectomy: surgical technique, indications and clinical results. Obes Surg 17: 1442-1450

27. Marshall JS, Srivastava A, Gupta SK, Rossi TR, DeBord JR (2003) Rouxen-Y gastric bypass leak complications. Arch Surg 138: 520-523.

28. Bhayani NH, Swanstrom LL (2014) Endoscopic therapies for leaks and fistulas after bariatric surgery. Surg Innov 21: 90-97.

29. van Boeckel PG, Sijbring A, Vleggaar FP, Siersema PD (2011) Systematic review: temporary stent placement for benign rupture or anastomotic leak of the esophagus. Aliment Pharmacol Ther 33: 1292-1301.

30. Casella G, Soricelli E, Rizzello M, Trentino P, Fiocca F, et al. (2009) Nonsurgical treatment of staple line leaks after laparoscopic sleeve gastrectomy. Obes Surg 19: 821-826.

31. Kowalski C, Kastuar S, Mehta V, Brolin RE (2007) Endoscopic injection of fibrina sealant in repair of gastrojejunostomy leak after laparoscopic Rouxen-Y gastric bypass. Surg Obes Relat Dis 3: 438-442.

32. Papavramidis ST, Eleftheriadis EE, Apostolidis DN, Kotzampassi KE (2001) Endoscopic fibrin sealing of high-output non-healing gastrocutaneous fistulas after vertical gastroplasty in morbidly obese patients. Obes Surg 11: 766-769.

33. Papavramidis ST, Eleftheriadis EE, Papavramidis TS, Kotzampassi KE, Gamvros OG (2004) Endoscopic management of gastrocutaneous fistula after bariatric surgery by using a fibrina sealant. Gastrointest Endosc 59: 296300.

34. Papavramidis TS, Kotzampassi K, Kotidis E, Eleftheriadis EE, Papavramidis ST (2008) Endoscopic fibrin sealing of gastrocutaneous fistulas after sleeve gastrectomy and biliopancreatic diversion with duodenal switch. J Gastroenterol Hepatol 23: 1802-1805.

35. Merrifield BF, Lautz D, Thompson CC (2006) Endoscopic repair of gastric leaks after Roux-en-Y gastric bypass: a less invasive approach. Gastrointest Endosc 63: 710-714.

36. Bege T, Emungania O, Vitton V, Ah-Soune P, Nocca D, et al. (2011) An endoscopic strategy for management of anastomotic complications from bariatric surgery: a prospective study. Gastrointest Endosc 73: 238-244.

37. Dakwar A, Assalia A, Khamaysi I, Kluger Y, Mahajna A (2013) Late complication of laparoscopic sleeve gastrectomy. Case Rep Gastrointest Med 2013: 136153 
Citation: Sigwalt MF, Wiederkehr JC, de Macedo RL, de Carvalho CA, Wiederkehr HA, et al. Endoscopic Treatment of Gastric Fundus Fistula after Sleeve Gastrectomy: A Case Report. J Surgery. 2014;2(2): 5.

ISSN: $2332-4139$

38. Branco-Filho AJ, Nassif LS, Menacho AM, Aurichio RAE, Siqueira DED, et al. (2011) Tratamento da obesidade mórbida com gastrectomia vertical. ABCD arq bras cir dig 24: 1

39. Rosenthal RJ, International Sleeve Gastrectomy Expert Panel, Diaz AA Arvidsson D, Baker RS, et al. (2012) International Sleeve Gastrectomy Expert Panel Consensus Statement: best practice guidelines based on experience of $>12,000$ cases. Surg Obes Relat Dis 8: 8-19.

40. Livingston EH (2005) Complications of bariatric surgery. Surg Clin North Am
Aug 85: 853-68.

41. Campos JM, Ishida RK, Fonseca AHF (2008) Diagnóstico de fístula gástrica e intestinal após cirurgia bariátrica. In: Campos JM, Galvão Neto MP, Moura EGH. Endoscopia em cirurgia da obesidade. 1a ed. São Paulo: Santos p.269-278.

42. Cortez M, Torres M, Herrera G, Zapata G, Monge B, et al. (2007) Gastrectomía vertical en manga laparoscópica: Análisis de los primeros ciento cincuenta casos. Asociación Mexicana de Cirugía Endoscópica, A.C. 8: 122-127. 